\title{
Using Autonomous Teams to Improve Quality of Life of People with Intellectual Disabilities
}

\author{
Marie Blížkovská ${ }^{1}$. Vicente Martínez-Tur ${ }^{2}$ D $\cdot$ Luminita Pătras $^{3}$ (D) \\ Carolina Moliner ${ }^{1}$ (D) Esther Gracia ${ }^{1}$ (D) José Ramos ${ }^{2}$ (D)
}

Received: 2 November 2020 / Accepted: 23 December 2021 / Published online: 9 February 2022

(C) The Author(s) 2022, corrected publication 2022

\begin{abstract}
This research study tested an intervention, based on autonomous teams and the service co-creation approach, to improve the social inclusion and self-determination (as indicators of quality of life) of people with intellectual disability. Members of the autonomous teams (professionals, people with intellectual disability, and family members) cooperated to plan and carry out a project. A total of 72 autonomous teams participated (experimental condition). Each team designed its action plan to be implemented during eight weeks. Three measurement times were used: before the intervention (T1), four (T2) and eight (T3) weeks after the starting point. Family members (experimental group, $N=117$; control group, $N=187$ ) reported on the social inclusion and self-determination of their relative with intellectual disability. Scores in the control group remained stable over time, whereas scores in the experimental group changed significantly. Social inclusion increased (T2), and later stabilized (T3). By contrast, self-determination increased (T2), but this improvement was subsequently reduced (T3).
\end{abstract}

Keywords Self-determination $\cdot$ Social inclusion $\cdot$ Autonomous teams

\section{MainText}

Estimates indicate that about $1 \%$ of the global population (more than 70 million people) have an intellectual disability (McKenzie et al., 2016). Although progress has been made, the social inclusion of people with intellectual disability persists in

Carolina Moliner

carolina.moliner@uv.es

1 Faculty of Psychology, IDOCAL-UVEG. Research Institute of Personnel Psychology, Organizational Development and Quality of Working Life, University of Valencia, Avenida Blasco Ibañez, 21.46010, Valencia, Spain

2 IDOCAL-UVEG E IVIE, Valencia, Spain

3 ESIC Business and Marketing School, Barcelona, Spain 
being a challenge in our societies that hinders the quality of life of this vulnerable group (United Nations, 2015). The lack of integration is linked to excessive institutionalization, lack of autonomy, overprotection by their families, and low employment levels (e.g., Maulik et al., 2011). One of the challenges to achieving inclusive contexts and independent living of people with intellectual disability is the cooperation between professionals in organizations and family members (Carter et al., 2013; Martínez-Tur et al., 2018). When the main efforts stem only from the professionals in organizations, there is not much hope for real improvement in the lives of people with intellectual disability. Family members must also become implicated in the process, but previous empirical evidence suggests that family members are less engaged in promoting the independent living of people with intellectual disability than professionals are (Martínez-Tur et al., 2018; Zhang et al., 2002; Zhang et al., 2005). Powers et al. (1996) attributed the family members' difficulties in stimulating social inclusion and self-determination in the decision-making of their relatives with intellectual disability to various factors: a) feelings of uncertainty about the expected level of self-determination; b) limited knowledge about strategies to enhance self-determination; and c) concerns about the risks of independent living (e.g., accidents). These factors can hinder the family members' effective collaboration with professionals to enhance social inclusion and self-determination of people with intellectual disability. The status of professionals in organizations can also limit opportunities for cooperation. There has been an increasing professionalization of organizations for people in need in modern societies (Carey et al., 2009), with positive outcomes, for example, in terms of using evidence-based knowledge. However, this knowledge is usually oriented toward decision-making and interactions with direct service users. By contrast, dialogue with stakeholders from the community (e.g., family members of people with intellectual disability) could be secondary in professionalized contexts (Alexander et al., 1999). Another challenge to achieving social inclusion and self-determination is the involvement of people with intellectual disability in decision-making about their own lives. Because of their disability, an important number of the decisions that affect them are made by others excluding them from the process. However, people with intellectual disability's involvement in decision-making has positive effects on them (e.g., Algozzine et al., 2001).

This study analyses the effects of an intervention based on autonomous teams and the service co-creation approach. Team members (professionals, people with intellectual disability, and family members) autonomously cooperated and designed the course of a project to improve the social inclusion and self-determination of the people with intellectual disability team members. This context, characterized by autonomy and cooperation, promotes the improvement of the quality of life of people with intellectual disability. Testing this intervention is innovative for at least three reasons. First, it extends the traditional objectives of autonomous teams. Typically, these teams focus on encouraging workers to become autonomous when they perform their tasks (Cherns, 1987). Workers are responsible, at least partially, for dividing the tasks, formulating working standards, and controlling quality and maintenance matters. The main goal is the improvement of aspects such as job satisfaction, efficiency, and quality control. By contrast, our autonomous teams deal with a social objective related to enhancing the quality of life of people with intellectual 
disability. More specifically, principles of autonomy and cooperation will make it possible to design and implement autonomous team working plans to increase the self-determination and social inclusion of people with intellectual disability. Second, we adopt a service co-creation approach based on the active role of the people with intellectual disability and their family members. Cooperation among professionals, people with intellectual disability, and family members is required for the adequate social inclusion of people with intellectual disability. Family members and people with intellectual disability are not only recipients of a service; they become co-creators of the service by defining it (e.g., Vargo \& Lusch, 2008). In our context, the active participation of service users is necessary to truly achieve the social inclusion and self-determination of people with intellectual disability as main organizational goals (Simoes \& Santos, 2007). Third, we conducted a randomized controlled trial study where participants are assigned to an experimental (they are involved in the working teams) vs. control group. In addition, we used three measurement times. The first assessment of social inclusion and self-determination is carried out before the intervention, and then four (T2) and eight (T3) weeks after the starting point. This design facilitates the examination of both the change in the assessed variables and the comparison in the different measures between the groups (experimental and control), providing a solid test of the intervention.

\section{Social Inclusion, Self-Determination, and Autonomous Teams}

In research on social inclusion, many terms are used interchangeably, thus creating confusion (Simplican et al., 2015). Nevertheless, in the organizations that provide services to persons with intellectual disability (e.g., Merrells et al., 2018), the definition of social inclusion by Wolfensberger (1998, p. 123) is generally accepted: "require valued participation, with valued people in valued activities that take place in valued settings". Social inclusion is a basic human need and a central feature of quality of life of people with intellectual disability (McIntyre et al., 2004). Research has concluded that the social involvement of people with intellectual disabilities is lower compared to people without intellectual disabilities because it is harder for them to create social bonds (Beart et al., 2005). This has a negative impact on the quality of life of people with intellectual disability. For instance, lower levels of social support have been linked to higher stress levels and greater likelihood of mental illness in people with intellectual disability (Scott \& Havercamp, 2014).

Regarding self-determination, it is well-known that autonomy is a basic human need (Ryan \& Deci, 2000). Humans have the desire to handle their own decisions in their lives and feel in control of what happens to them. People with intellectual disability have the same needs because constructs describing quality of life are universally applicable to the general population and to people with intellectual disability (Morisse et al., 2013). Scholars and practitioners typically include people with intellectual disability's need for autonomy under the umbrella of the self-determination concept: "volitional actions that enable one to act as the primary causal agent in one's life and to maintain or improve one's quality of life" (Wehmeyer, 2005, p. 117). The importance attributed to the self-determination of people with intellectual 
disability is grounded on research that confirms its benefits for academic performance (Seong et al., 2015; Webster et al., 2017), employability (Field \& Hoffman, 2007; Shogren et al., 2015), independent living (Palmer \& Wehmeyer, 2003), and quality of life in general (Lachapelle et al., 2005).

Social inclusion and self-determination are the areas that receive the most attention in organizations that aim to improve personal growth and quality of life of people with intellectual disability (Lachapelle et al., 2005; Wehmeyer \& Shogren, 2016). Generally speaking, these two areas (social inclusion and selfdetermination) allow better social integration of people with intellectual disability, significantly improving their quality of life (Kober \& Eggleton, 2006; McDougall et al., 2016). There are relevant efforts to stimulate self-determination of people with intellectual disability inside institutions (e.g., schools), for example, through skills training (Kelley et al., 2013). Social inclusion is also stimulated by providing access to resources and establishing a closer relationship with the local community. Specific actions are helpful, such as facilitating the access of people with intellectual disability to transportation (e.g., Wasfi et al., 2017). However, the impact is limited if family members and people with intellectual disability are not involved in the organizational life and do not cooperate with professionals as co-creators of the service. Cooperation among professionals, people with intellectual disability, and family members is necessary to enhance social inclusion and self-determination and extend people with intellectual disability's opportunities for social integration and independent living beyond institutions (Carter et al., 2013; Martínez-Tur et al., 2018).

This participative rationale is present in autonomous teams. In the second half of the twentieth century, members of the Hawthorne Institute (London) were pioneers in using autonomous teams. For example, Trist et al. (1977) carried out an action research project, based on autonomous teams at an underground coal mine, with positive effects on safety, job satisfaction, and performance. Further studies confirmed the significant role of autonomous teams in predicting relevant outcomes. Although the magnitude of the positive results of autonomous teams probably depends on contingency factors (Magpili \& Pazos, 2018; Park, 2012), research has shown benefits such as productivity (Cohen \& Ledford, 1994), job satisfaction (Batt, 2004), organizational commitment (Riordan et al., 2005), and organizational citizenship behavior (Cappelli \& Rogovsky, 1998). There are relevant differences between the characteristics of teams in the aforementioned research studies and the autonomous teams involved in the current investigation. First, our goals are different. Typically, autonomous teams focus on workers' autonomy to decide on the organization of tasks, obtaining benefits related to performance, productivity, and workers' attitudes. By contrast, our autonomous teams concentrate on the planification and implementation of the plan that aims to improve the social inclusion and self-determination of people with intellectual disability. Therefore, improving the quality of life of people in need (i.e., people with intellectual disability) is the predominant objective. Second, traditional autonomous teams include workers as members, whereas the autonomous teams in our study also incorporate people with 
intellectual disability and family members. Our autonomous-teams design is based on the service co-creation approach (Neghina et al., 2015; Vargo \& Lusch, 2008). Thus, the service user is not a passive recipient, but rather an active participant in the organizational life and in the definition of the service. This is especially relevant in the definition of the service because, although the involvement of family members is essential to enhance people with intellectual disability's independence (Carter et al., 2013), obstacles to this participation still exist (Martínez-Tur et al., 2018; Powers et al., 1996).

Autonomous teams are the appropriate way to stimulate social inclusion and selfdetermination of people with intellectual disability through social interaction and autonomy. In a correlational study, Martínez-Tur et al. (2018) observed, based on the mere-exposure effect (e.g., Young et al., 2016; Zajonc, 1968), that dialogue between professionals and family members increased their view of independent living of people with intellectual disability as a valuable objective. This dialogue exposed both actors to goals related to social inclusion and self-determination of people with intellectual disability, facilitating positive views about people with intellectual disability's independence. We propose that autonomous teams would help to remove obstacles by taking two more steps. First, our autonomous teams focus on specific projects. In addition to dialogue and exposure to concerns and opportunities related to the quality of life of people with intellectual disability, participants have to design and implement an action plan to enhance self-determination and social inclusion of the team members with intellectual disability. Therefore, there is a transference from the social interaction of participants to the real life of people with intellectual disability. Second, people with intellectual disability also participate in the team, increasing the viability of the project and its fit to their interests and needs.

Participants are free to autonomously design the project to be implemented. This autonomy not only satisfies a basic human need (Deci \& Ryan, 2000), but it is also a way to increase motivation through a sense of choice and free will (Nelson et al., 2014). Congruent with this argument, Algozzine et al. (2001) found that involving adolescents with intellectual disability in decision-making about their education promotes a smooth transition from school to their future life. It is also reasonable to expect that autonomy plays a positive motivational role for participants in autonomous teams, especially family members and people with intellectual disability. Actions are not implemented unilaterally. Instead, family members and people with intellectual disability are co-creators of the project through their participation in the organizational life and cooperation with professionals in the autonomous teams as co-creators of the service.

Based on these arguments, we put forward that the involvement of professionals, people with intellectual disability, and family members in autonomous teams will improve the social inclusion and self-determination of team members with intellectual disability. To test this proposal, we conducted a randomized controlled trial study in real organizations that offer services for people with intellectual disability. 


\section{Method}

\section{Participants and Procedure}

We followed the principles of the Declaration of Helsinki. The ethical Committee of the research team university approved the study. Researchers explained the objectives of the study to participants. Participation was anonymous and confidential. A total of 59 organizations for people with intellectual disability (sheltered workshops) participated in the study. In these organizations, persons with intellectual disability's work are supervised, with the final goal of their incorporation into the labor market and/or improving their social inclusion. All organizations were affiliated with "Plena inclusión", an NGO in Spain whose mission is to achieve better live conditions and social inclusion of people with intellectual disability. In each organization at least one team $(N=72)$ was created with the participation of two professionals, two people with intellectual disabilities and two family members. One people with intellectual disability and one of his/her family members (the relative who had regular interaction with the organization) represented each family in the autonomous team. A different group of family members per center was also randomly selected for the control group. One professional per center was trained by the research team to randomly select the participants in both the control and experimental groups. General participation rates in the project were very high $(95.78 \%)$. In this study we analyze the perspective of the family members. The final sample for all three measurement times for the statistical analyses consisted of 117 relatives in the experimental group (autonomous teams) and 187 relatives in the control group. About $76.9 \%$ of the family members in the autonomous teams (average age $=58,20 ; S D=10.42$ ) were women. About $77.2 \%$ of the family members in the control group (average age $=56,07 ; S D=10.83$ ) were women.

For each autonomous team, one researcher played the role of facilitator, following a standardized procedure. The facilitator explained the idea and procedure to the participants involved in the project, clarified the objectives (improving social inclusion and self-determination of people with intellectual disability who participated in the autonomous team), and stimulated creativity. A participative approach was followed where two professionals, two people with intellectual disability, and two family members participated in the decision-making about the plan to be implemented by the team. After the facilitator speech, autonomous teams were free to design the plan to be implemented. They had to design a plan to improve the social inclusion and self-determination of the people with intellectual disabilities, specifying the course of the action plan to stimulate the access to resources and establish a closer relationship with the local community. All the autonomous teams had the same time frame (two hours) and the same procedure to follow in designing the action plan. In defining the plan, one relevant criterion was the consideration of autonomy because it has a motivational effect on participants. Another important criterion was the co-creation process. The designed plan was not implemented unilaterally but family members and people with intellectual disabilities were directly involved. They then executed the plan during the following 8 weeks. Family members and people 
with intellectual disability pertaining to the control group were not informed about the creation of autonomous teams. To provide an external view beyond the institutions, family members reported on social inclusion and self-determination of their relatives with intellectual disability. We considered the family member a suitable informant. Parents are able to see the behaviors related to self-determination and social inclusion in natural contexts beyond the organization. It should be taken into consideration that the action plan designed and to be implemented by the autonomous team must be linked to the natural context of the person with disabilities; that is, it is designed to go beyond the organization. In these natural contexts where the action plan is to be implemented, family members are the best informants to see the behavior of the person with a disability in terms of self-determination and social inclusion. There were the same three measurement times: before the initial session (Time 1) and four (Time 2) and eight (Time 3) weeks after the starting point (initial session). We decided on a duration of eight weeks in agreement with "Plena inclusion", the NGO participating in the project. The experts in this organization indicated that eight weeks was an adequate period to develop the projects. In addition, we looked for eight-week periods when there were no holidays that would interrupt the teams' work. Finally, we introduced the measure of four weeks to have a control in the middle of the process. Both the experimental and control groups followed the same calendar.

\section{Differences in Baseline}

No significant differences were found between relatives distributed to the experimental (autonomous teams) vs. control groups in age $\left(\mathrm{t}_{(299)}=-1.69, p>0.05\right)$, sex distribution $\left(\chi^{2}(1)=0.003, p>0.05\right)$, or level of education $\left(\chi^{2}(3)=0.371, p>0.05\right)$ meaning absence of biases. Regarding the persons with intellectual disability, the severity of their disability was very similar in the autonomous teams (average severity $=68.67, \mathrm{SD}=11.44$ ) and in the control group (average severity $=68.87$, $\mathrm{SD}=11.20)$. Furthermore, no significant differences were found in age $(\mathrm{t}$ $\left.{ }_{(467)}=1.58, p>0.05\right)$ or sex distribution $\left(\chi^{2}(1)=0.525, p>0.05\right)$ of the persons with intellectual disability involved in the teams.

\section{Measures}

We measured self-determination and social inclusion by using the scales validated by Moliner et al. (2013). These scales focus on improvements in these two facets of quality of life of people with intellectual disability because of the actions of sheltered workshops. Therefore, this measure made it possible to pay attention to improvements based on actions of the organizations where the autonomous teams are located. The measure not only considers self-determination and social inclusion, but also to what degree they improve thanks to the efforts of the organization. This measure is especially suitable in our study because the objective is to analyze to what extent a collective effort in the organization (the autonomous teams) leads to an improvement in self-determination and social inclusion. In addition, each family 
member responded with his/her relative with intellectual disability in mind. An example of an item on the 5-item self-determination scale is "I have observed an increase in the possibilities of self-management and independence of the person with intellectual disabilities for whom I am responsible, thanks to this center". Reliability scores for this scale were $\alpha=0.86, \alpha=0.85$, and $\alpha=0.88$ for $\mathrm{T} 1, \mathrm{~T} 2$, and T3, respectively. An example of an item on the 4-item social inclusion scale is "The social integration of my relative with disabilities has improved, thanks to the actions developed by this center". Reliability scores for this scale were $\alpha=0.88, \alpha=0.91$, and $\alpha=0.92$ for T1, T2, and T3, respectively. Each one of the items on both scales followed on a Likert scale ranging from 1 ("strongly disagree") to 7 ("strongly agree"). We analyzed the differentiation between the two dimensions of quality of life by computing a Harman's single-factor test (Podsakoff et al., 2003). To this end, we ran Confirmatory Factor Analysis in Mplus, comparing a two-factor model that included both social and self-determination inclusion with a single-factor model specifying that all indicators would load into one general factor. The results confirmed that the two-factor model fits the data better $(\chi 2=101.244, \mathrm{df}=26, p<0.01$, RMSEA $=0.09(90 \% \mathrm{CI}=0.08,0.11), \mathrm{CFI}=0.95, \mathrm{TLI}=0.93, \mathrm{SRMR}=0.05)$, than the alternative one-factor model $(\chi 2=208.815, \mathrm{df}=27, p<0.01$, RMSEA $=0.149$ $(90 \% \mathrm{CI}=0.13,0.16), \mathrm{CFI}=0.89$, TLI $=0.85, \mathrm{SRMR}=0.05)$ as the fit indices for the one-factor model were lower than the cut-off $(\mathrm{RMSEA}<0.10 ; \mathrm{CFI}>0.90$; TLI>0.90), whereas the fit of the two-factor model was satisfactory. When comparing both models, significant differences were found $(\Delta \chi 2=106.94, \Delta \mathrm{df}=1$, $p<0.001$ ), supporting social inclusion and self-determination as two distinct constructs. Differences between the constructs of social inclusion and self-determination were also examined between the groups (experimental and control) in time 1 (pre-intervention step). Results from the analyses of simple effects showed that there are no significant differences in either self-determination $\left(\mathrm{F}_{(1,303)}=0.021, p>0.05\right)$, nor for social inclusion $\left(\mathrm{F}_{(1,303)}=1.32, p>0.05\right)$, comparing both groups (the experimental vs. control) in the phase that corresponded to pre-intervention.

\section{Analyses}

Repeated-measures ANOVAs were performed to determine whether the intervention had an effect on the levels of social inclusion and self-determination across the three measurement times. The main effects of the independent factors, time (T1, T2, and T3) and condition (experimental vs. control group), were examined first to test the effect on social inclusion and self-determination. Next, the interaction effect of time and condition (experimental vs. control group) was assessed for social inclusion and self-determination.

\section{Results}

Descriptive analyses and correlations among variables appear in Table 1. Positive and significant relations existed among the measures of self-determination and social inclusion, reported by relatives. 
Table 1 Descriptive statistics and correlations among dependent variables

\begin{tabular}{lllllllll}
\hline & $M$ & $S D$ & 1 & 2 & 3 & 4 & 5 & 6 \\
\hline 1. T1-Self-determination & 5.9 & 1.05 & $(.863)$ & & & & & \\
2. T1-Social Inclusion & 6.03 & .90 & $.748^{* *}$ & $(.880)$ & & & & \\
3. T2-Self-determination & 6.02 & .89 & $.623^{* *}$ & $.479 * *$ & $(.855)$ & & & \\
4. T2-Social Inclusion & 6.14 & .90 & $.491 * *$ & $.549 * *$ & $.683 * *$ & $(.914)$ & & \\
5. T3-Self-determination & 6.01 & .96 & $.592^{* *}$ & $.509 * *$ & $.670^{* *}$ & $.494 * *$ & $(.881)$ & \\
6. T3-Social Inclusion & 6.1 & .95 & $.475^{* *}$ & $.545^{* *}$ & $.570^{* *}$ & $.599 * *$ & $.766^{* *}$ & $(.918)$ \\
\hline
\end{tabular}

${ }^{* *} p<.01$. Alpha coefficients are along the diagonal

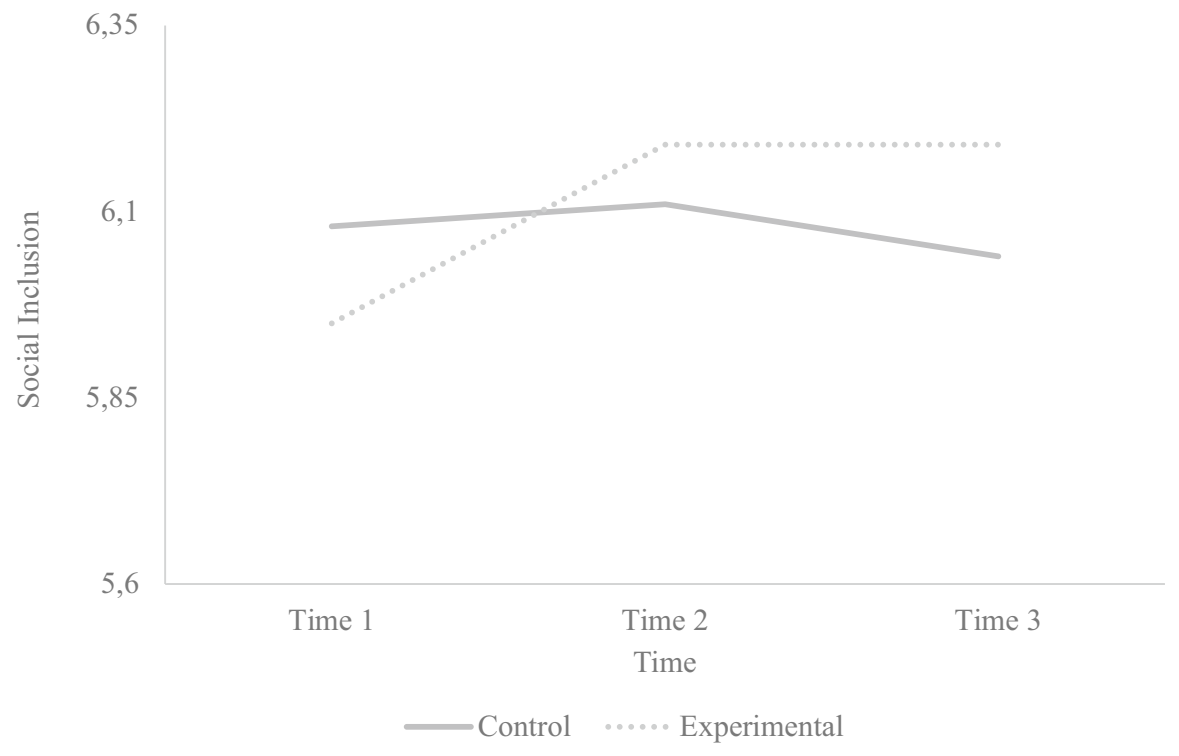

Fig. 1 Effect of the interaction of time and condition on the social inclusion of PID

Regarding social inclusion, results show a significant linear direct effect of time $\left(F_{(2,302)}=3.878, p<0.05, \eta=0.021\right)$. However, the direct effect of condition (experimental vs. control group) $\left(\mathrm{F}_{(2,302)}=0.020, p>0.05, \eta=0.001\right.$ ) was not statistically significant. By contrast, the interaction (time $\mathrm{x}$ condition) was statistically significant $\left(\mathrm{F}_{(2,302)}=4.141, p<0.05, \eta=0.014\right)$. Compared to the control group, social inclusion of team members (experimental group) with intellectual disability, reported by family members, improved over time (see Fig. 1). Because relatives belong to different centers, and centers may differ to the extent they enhance social inclusion, center membership could impact our results. Having this in mind, we computed supplementary analyses to control for center membership of family members. This allowed us to test whether the significant interaction (between time and interaction) we observed can be replicated regardless of the center. In particular, we performed regression models (mixed-effect) with 


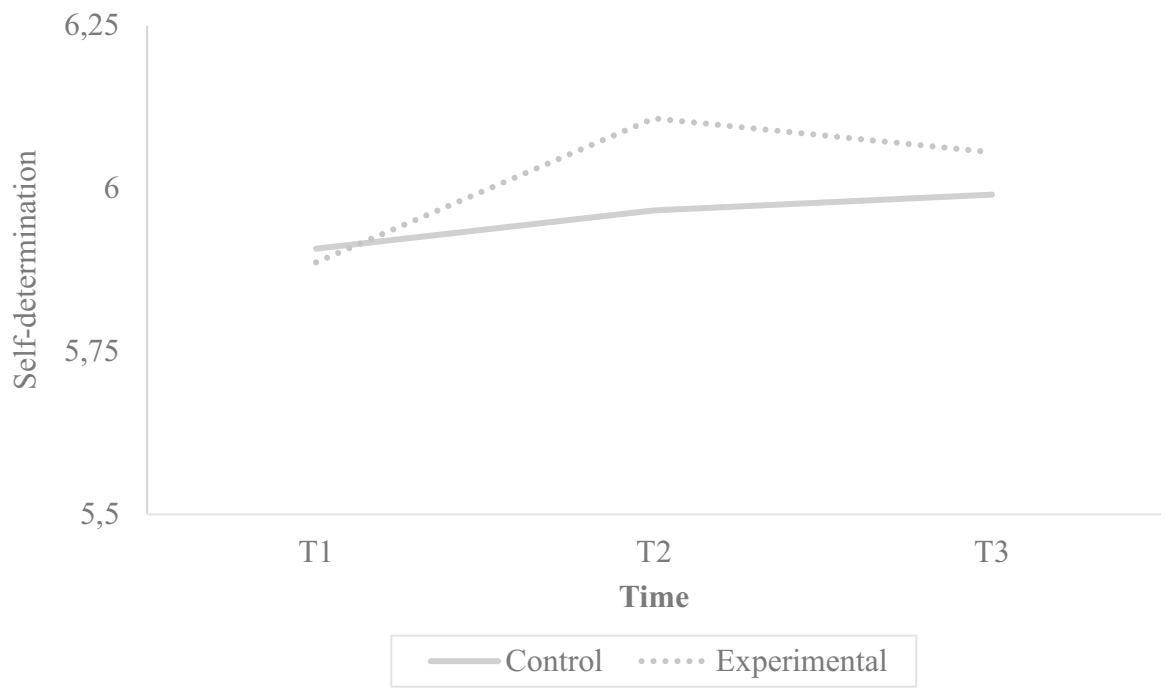

Fig. 2 Effect of the interaction of time and condition on self-determination of PID

random intercepts to examine change discrepancies in the social inclusion score over time between the experimental and control groups, once we controlled for belongingness to the center. Results confirmed again that the interaction of time (T1; T2; and T3) and condition (experimental vs. control groups) was statistically significant $\left(F_{(1,618)}=7.39, p<0.005\right)$. Involvement in projects (experimental group) improved social inclusion of people with intellectual disability over time, compared with the control group, with a significant difference in the slopes $\left(b=0.14, t_{(618)}=2.72, p<0.05\right)$.

Results were different for self-determination. Repeated-measures ANOVAs showed that time had a significant linear direct effect $\left(F_{(2,302)}=4.953, p<0.05\right.$, $\eta=0.016$ ). However, the direct linear effect of condition (experimental vs. control groups) $\left(F_{(2,302)}=0.338, p>0.05, \eta=0.001\right)$ nor the interaction term were statistically significant $\left(F_{(2,302)}=1.239, p>0.05, \eta=0.004\right)$ (see Fig. 2). We also confirmed this lack of significant interaction between time and condition (experimental vs. control groups) computing a mixed-effect regression model where center membership of families was controlled for $\left(\mathrm{F}_{(1,619)}=0.664, p>0.05\right)$ with a non-significant difference in the slopes $\left(\mathrm{b}=0.04, \mathrm{t}_{(619)}=0.81, p>0.05\right)$.

\section{Auxiliary information ${ }^{1}$}

To better capture how the variables evolved over time, we also checked quadratic effects. For social inclusion, the results of the ANOVA showed a significant quadratic effect of time $\left(\mathrm{F}_{(1,302)}=3.907, p<0.05, \eta=0.013\right)$. Specifically, the changes

\footnotetext{
1 The authors want to thank the anonymous reviewer who suggested analyzing quadratic effects.
} 
across time indicated a significant increase in the level of social inclusion from Time $1(M=6.01, S D=0.05)$ to Time $2(M=6.15, S D=0.05)$. However, the change in social inclusion from Time 2 to Time 3 was not significant $(M=6.12, S D=0.05)$. The effect of condition (experimental vs. control group) did not show a statistically significant quadratic effect $\left(\mathrm{F}_{(1,302)}=0.152, p>0.05\right)$. The interaction between time and condition had a statistically significant quadratic effect on social inclusion. Time had a significant effect on the autonomous teams $\left(\mathrm{F}_{(2,302)}=5.652, p<0.05\right)$, but not on the control group $\left(\mathrm{F}_{(2,302)}=0.656, p>0.05\right)$. Participating in the experimental condition made it possible to increase, and later stabilize, the social inclusion of people with intellectual disabilities (see Fig. 1).

For self-determination, the results of the ANOVA analysis showed a significant quadratic effect of time $\left(\mathrm{F}_{(1,302)}=3.907, p<0.05, \eta=0.013\right)$. Specifically, the changes across time indicated a significant increase in the level of self-determination from Time $1(M=5.89, S D=0.06)$ to Time $2(M=6.04, S D=0.05)$. However, from Time 2 to Time $3(M=6.02, S D=0.05)$, change was no significant. The effect of condition (experimental vs. control group) did not show a statistically significant quadratic effect $\left(\mathrm{F}_{(1,302)}=0.392, p>0.05\right)$. The interaction between time and condition had a statistically significant quadratic effect on self-determination. Time had a significant effect on the autonomous teams $\left(\mathrm{F}_{(2,302)}=3.927, p<0.05\right)$, but not on the control group $\left(\mathrm{F}_{(2,302)}=0.853, p>0.05\right)$. Participating in the experimental condition increased self-determination (T2), but this improvement was subsequently reduced (T3), describing a curvilinear dynamic (see Fig. 2).

\section{Discussion}

The current research study sought to determine whether participation of professionals, people with intellectual disability, and family members in autonomous teams enhances the social inclusion and self-determination of people with intellectual disability over time, reported by family members. To answer this research question, we conducted a randomized controlled trial study in real organizations for people with intellectual disability. Compared to the control group, participating in an autonomous team improved the social inclusion of people with intellectual disability after four weeks (T2), and then stabilized after eight weeks (T3). Self-determination also increased (T2), but this improvement was subsequently reduced (T3).

The positive impact of autonomous teams on the social inclusion of people with intellectual disability is especially relevant. Social inclusion continues to be one of the critical challenges in improving the quality of life of people with intellectual disability, even in developed countries (United Nations, 2015). Although evidence has shown benefits of social inclusion for people with intellectual disabilities, important obstacles still exist (Maulik et al., 2011; McKenzie et al., 2016). Therefore, confirming the existence of interventions and organizational practices that improve social inclusion could open the door to new practices in organizations for people with intellectual disability and in services for vulnerable people in general. It is wellknown that family members are less engaged in promoting the independent living of their relatives with intellectual disability than professionals are (Zhang et al., 2002, 
2005). It is also possible that professionals with high levels of expertise do not open up genuine channels of communication with relevant actors in the community (i.e., family members) (Alexander et al., 1999). Finally, there could be some inertia in making decisions about the life of people with intellectual disability without considering their perspective. The creation of autonomous teams helps to overcome this separation of three relevant actors who, paradoxically, share the same goal (promoting a better life for people with intellectual disability) and can achieve it better if they work together. The autonomous team seems to be an adequate context within organizational life to involve professionals, people with intellectual disability, and family members through participation and autonomy. Together, they are involved in the challenge of improving the social inclusion of the team members with intellectual disability, and they have the autonomy to choose what project to implement. The autonomy that characterizes these teams is motivating in itself because it is associated with a sense of choice and initiative (Deci \& Ryan, 2000; Nelson et al., 2014) that facilitates the design and implementation of successful projects to improve social inclusion of people with intellectual disability.

Other relevant contributions of this research study are related to two specific characteristics of our autonomous teams. First, autonomous teams can produce outcomes that go beyond the role traditionally attributed to this type of team. Typically, autonomous teams are designed to make members participate in decision-making about the organization of aspects such as tasks, quality control, and maintenance, with positive effects in terms of performance (e.g., Cohen \& Ledford, 1994) and job attitudes (e.g., Batt, 2004). However, our results confirm that other social objectives can be achieved. For organizations whose main goal has a social nature (i.e., improving social inclusion of people with intellectual disability), the organization of autonomous teams is an interesting option to expand the available strategies. Second, traditional autonomous teams are composed of workers. By contrast, our findings suggest that incorporating service users (people with intellectual disability and family members) into the team can be quite useful, based on a co-creation approach that promotes the active participation of users in the definition of services (Neghina et al., 2015; Vargo \& Lusch, 2008). The autonomous team is a good context in which to stimulate co-creation through the necessary participation of professionals, people with intellectual disability, and family members, in order to improve the social inclusion of people with intellectual disability.

Our results have relevant practical implications. Managers and professionals in organizations for people with intellectual disability should be aware that investing resources in organizing autonomous teams is a good strategy for improving social inclusion. It requires not only the involvement of professionals, but also the active involvement of people with intellectual disability and family members as co-creators of projects. In a number of organizations, this probably requires a change in the mentality of organizational members, who should create real contexts for joint participation and autonomy in the decision-making of professionals, people with intellectual disability, and family members. It is not easy. In organizations with social objectives, there is an increasing tendency towards professionalization and bureaucratization (Carey et al., 2009). This process probably has positive aspects (e.g., standardization of the service delivery to provide equal treatment for all users, use of 
expertise), but it should be combined with continued actions over time (i.e., autonomous teams) where innovation and creativity emerge to promote the social inclusion of people with intellectual disability.

Our intervention based on autonomous teams did not have the expected effect on the other facet of quality of life of people with intellectual disability we considered: self-determination. Although there was a positive effect after four weeks, this change tended to disappear after eight weeks. It is difficult to maintain an improvement over time. A provisional explanation for this unexpected result could be connected to the differential nature of social inclusion vs. self-determination. Unlike social inclusion, it is possible that self-determination is more difficult for autonomous teams to change. Self-determination is probably intimately associated with the degree of disability severity of each individual with intellectual disability, and changes are only possible through the use of very specialized knowledge. By contrast, improvements in social inclusion may be easier for autonomous teams to obtain because organizing activities that facilitate the integration of people with intellectual disability (e.g., leisure) is more contextual in nature and can be achieved if there is cooperation and support among team members. Future studies should examine whether the severity of the disability plays a role in understanding possible changes in self-determination through autonomous teams. Another possible explanation of the unexpected result could be related to the measure of self-determination we used. Our measure considered the improvement in self-determination thanks to the efforts of the organization, which includes the performance of the teams. Perhaps this evaluation is too general, and future studies could use another measure to capture the changes in the specific achievements of the teams where professionals and families participate.

Limitations of this study provide input for future studies. First, the intervention we tested is focused on a concrete organizational context for people with intellectual disability: sheltered workshops. Although these centers share some critical characteristics with other types of organizations (e.g., education centers for people with intellectual disability), such as carrying out actions for a smooth transition to independent living, the replication of this intervention in other organizational contexts will offer information about its generalizability. Second, family members were the source of information used to assess the improvement in social inclusion and selfdetermination, in order to provide a perspective that goes beyond the institution. However, in future studies, other indicators, such as objective measures, could enrich the information about changes in self-determination and social inclusion. Finally, autonomous teams with two professionals, two persons with disability and two relatives could produce richer exchanges and creativity, but a dispersion of ideas might also be present. It would be enriching to explore the effects in smaller teams where a dyad of professionals and family members jointly cooperate with the relative with intellectual disability to improve his/her social inclusion and self-determination.

In sum, our study contributes to the literature about improving the quality of life of people with intellectual disability by testing an intervention based on autonomous teams and service co-creation. Social inclusion of people with intellectual disability is a critical challenge in today's societies, and it requires new ideas and efforts. According to our results, the use of autonomous teams emerges as an interesting and useful strategy to improve the social inclusion of people with intellectual disability 
over time. Achieving this change in the quality of life of people with intellectual disability is possible thanks to the active cooperation of professionals, people with intellectual disability, and family members.

Acknowledgements This research study was carried out under one of the projects supported by the "Agencia Estatal de Investigación en España" (PSI2016-78158-R) and FEDER. The authors would like to thank "Plena inclusion" and associated centers that participated in the study, especially professionals, families and people with intellectual disability.

All data are fully available without restriction.

Funding Open Access funding provided thanks to the CRUE-CSIC agreement with Springer Nature. The research leading to these results received funding from the "Agencia Estatal de Investigación en España” under Grant Agreement No PSI2016-78158-R, and FEDER.

\section{Declarations}

Ethical approval The study was conducted in accordance with the Declaration of Helsinki and it was evaluated and approved by the Ethical Committee of the University of Valencia.

Consent All participants were briefed about the objectives of the study and gave their written and informed consent. Anonymity and confidentiality were guaranteed by the researchers. In addition, participants were informed that they were free to leave the study at any time or prevent the use of the data they provided.

Conflicts of interest/Competing interests The authors have no conflicts of interest to declare that are relevant to the content of this article.

Open Access This article is licensed under a Creative Commons Attribution 4.0 International License, which permits use, sharing, adaptation, distribution and reproduction in any medium or format, as long as you give appropriate credit to the original author(s) and the source, provide a link to the Creative Commons licence, and indicate if changes were made. The images or other third party material in this article are included in the article's Creative Commons licence, unless indicated otherwise in a credit line to the material. If material is not included in the article's Creative Commons licence and your intended use is not permitted by statutory regulation or exceeds the permitted use, you will need to obtain permission directly from the copyright holder. To view a copy of this licence, visit http://creativecommons.org/licen ses/by/4.0/.

\section{References}

Alexander, J., Nank, R., \& Stivers, C. (1999). Implications of welfare reform: Do nonprofit survival strategies threaten civil society? Nonprofit and Voluntary Sector Quarterly, 28(4), 452-475. https://doi. org/10.1177/0899764099284005

Algozzine, B., Browder, D., Karvonen, M., Test, D. W., \& Wood, W. M. (2001). Effects of Interventions to Promote Self-Determination for Individuals With Disabilities. Review of Educational Research, 71(2), 219-277. https://doi.org/10.3102/00346543071002219

Batt, R. (2004). Who Benefits from Teams? Comparing the Outcomes for Managers, Supervisors, and Workers. Industrial Relations, 43(1), 183-212.

Beart, S., Hardy, G., \& Buchan, L. (2005). How people with intellectual disabilities view their social identity: A review of the literature. Journal of Applied Research in Intellectual Disabilities, 18(1), 47-56. https://doi.org/10.1111/j.1468-3148.2004.00218.x 
Cappelli, P., \& Rogovsky, N. (1998). Employee Involvement and Organizational Citizenship: Implications for Labor Law Reform and Lean Production. Industrial and Labor Relations Review, 51(4), 633-653.

Carey, G., Braunack-Mayer, A., \& Barraket, J. (2009). Spaces of care in the third sector: Understanding the effects of professionalization. Health: An Interdisciplinary Journal for the Social Study of Health. Illness and Medicine, 13, 629-646. https://doi.org/10.1177/1363459308341866

Carter, E. W., Lane, K. L., Cooney, M., Weir, K., Moss, C. K., \& Machalicek, W. (2013). Parent assessments of self-determination importance and performance for students with autism or intellectual disability. American Journal on Intellectual and Developmental Disabilities, 118(1), 16-31.

Cherns, A. (1987). Principles of Sociotechnical Design Revisited. (The Tavist). London: Sage.

Cohen, S. G., \& Ledford, G. E. (1994). The Effectiveness of Self-Managing Teams: A Field Experiment. Human Relations, 47, 13-43.

Field, S., \& Hoffman, A. (2007). Self-Determination in Secondary Transition Assessment. Assessment for Effective Intervention, 32(3), 181-190. https://doi.org/10.1177/15345084070320030601

Kelley, K. R., Bartholomew, A., \& Test, D. W. (2013). Effects of the Self-Directed IEP Delivered Using Computer-Assisted Instruction on Student Participation in Educational Planning Meetings. Remedial and Special Education, 34(2), 67-77. https://doi.org/10.1177/0741932511415864

Kober, R., \& Eggleton, I. R. C. (2006). Using Quality of Life to Asses Performance in the disability Service Sector. Applied Research in Quality of Life, 1, 63-77. https://doi.org/10.1007/ s11482-006-9005-Z

Lachapelle, Y., Wehmeyer, M. L., Haelewyck, M.-C., Courbois, Y., Keith, K. D., Schalock, R., ... Walsh, P. N. (2005). The relationship between quality of life and self-determination: an international study. Journal of Intellectual Disability Research, 49(10), 740-744. https://doi.org/10.1111/j.1365-2788. 2005.00743.x

Magpili, N. C., \& Pazos, P. (2018). Self-Managing Team Performance: A Systematic Review of Multilevel Input Factors. Small Group Research, 49(1), 3-33. https://doi.org/10.1177/1046496417710500

Martínez-Tur, V., Estreder, Y., Moliner, C., Gracia, E., Pătraș, L., \& Zornoza, A. (2018). Dialogue between workers and family members is related to their attitudes towards self-determination of individuals with intellectual disability. Journal of Intellectual \& Developmental Disability, 43(3), 370-379. https://doi.org/10.3109/13668250.2017.1416256

Maulik, P. K., Mascarenhas, M. N., Mathers, C. D., Dua, T., \& Saxena, S. (2011). Prevalence of intellectual disability: A meta-analysis of population-based studies. Developmental Disabilities, 32(2), 419-436. https://doi.org/10.1016/j.ridd.2010.12.018

McDougall, J., Baldwin, P., Evans, J., Nichols, M., Etherington, N., \& Wright, V. (2016). Quality of life and self-determination: Youth with chronic health conditions make the connection. Applied Research Quality Life, 11, 571-599. https://doi.org/10.1007/s11482-014-9382-7

McIntyre, L. L., Kraemer, B. R., Blacher, J., \& Simmerman, S. (2004). Quality of life for young adults with severe intellectual disability: Mothers' thoughts and reflections. Journal of Intellectual \& Developmental Disability, 29(2), 131-146. https://doi.org/10.1080/13668250410001709485

McKenzie, K., Milton, M., Smith, G., \& Ouellette-Kuntz, H. (2016). Systematic Review of the Prevalence and Incidence of Intellectual Disabilities: Current Trends and Issues. Current Developmental Disorders Reports, 3(2), 104-115. https://doi.org/10.1007/s40474-016-0085-7

Merrells, J., Buchanan, A., \& Waters, R. (2018). The experience of social inclusion for people with intellectual disability within community recreational programs: A systematic review. Journal of Intellectual \& Developmental Disability, 43(4), 381-391. https://doi.org/10.3109/13668250.2017.1283684

Moliner, C., Gracia, E., Lorente, L., \& Martínez-Tur, V. (2013). Structure and validation of a contextual Quality of Life scale for people with intellectual disabilities in social services: An organization oriented measure from an External perspective. Perspectivas Em Gestão \& Conhecimento, 3, 80-94.

Morisse, F., Vandemaele, E., Claes, C., Claes, L., \& Vandevelde, S. (2013). Quality of life in persons with intellectual disabilities and mental health problems: An explorative study. The Scientific World Journal, 2013. https://doi.org/10.1155/2013/491918

Neghina, C., Caniëls, M. C. J., Bloemer, J. M. M., \& van Birgelen, M. J. H. (2015). Value cocreation in service interactions: Dimensions and antecedents. Marketing Theory, 15(2), 221-242. https://doi. org/10.1177/1470593114552580 
Nelson, S. K., Della Porta, M. D., Jacobs Bao, K., Lee, H. C., Choi, I., \& Lyubomirsky, S. (2014). 'It's up to you': Experimentally manipulated autonomy support for prosocial behavior improves well-being in two cultures over six weeks. The Journal of Positive Psychology, 9760(September), 1-14. https:// doi.org/10.1080/17439760.2014.983959

Palmer, S. B., \& Wehmeyer, M. L. (2003). Adult Outcomes for Students with Cognitive Disabilities Three-Years After High School: The Impact of Self-Determination. Education and Training in Developmental Disabilities, 38(2), 131-144.

Park, R. (2012). Self-managing teams and employee attitudes: The moderating role of capital intensity. The International Journal of Human Resource Management, 23(4), 714-730. https://doi.org/10. 1080/09585192.2011.561212

Powers, L. E., Wilson, R., Matuszewski, J., Phillips, A., Rein, C., \& Schumacher, D. Gensert, J. (1996). Facilitating adolescent self-determination: What does it take? In D. J. Sands \& M. L. Wehmeyer (Eds.), Self-determination across the life span: Independence and choice for people with disabilities (pp. 257-284). Baltimore: MD: Brooks.

Riordan, C. M., Vandenberg, R. J., \& Richardson, H. A. (2005). Employee involvement climate and organizational effectiveness. Human Resource Management, 44(4), 471-488. https://doi.org/10. 1002/hrm.20085

Ryan, R. M., \& Deci, E. L. (2000). Self-determination theory and the facilitation of intrinsic motivation, social development, and well-being. American Psychologist, 55(1), 68-78. https://doi.org/10.1037/ 0003-066X.55.1.68

Scott, H. M., \& Havercamp, S. M. (2014). Mental Health for People With Intellectual Disability: The Impact of Stress and Social Support. American Journal on Intellectual and Developmental Disabilities, 119(6), 552-564. https://doi.org/10.1352/1944-7558-119.6.552

Seong, Y., Wehmeyer, M. L., Palmer, S. B., \& Little, T. D. (2015). Effects of the self-directed individualized education program on self-determination and transition of adolescents with disabilities. Career Development and Transition for Exceptional Individuals, 38(3), 132-141. https://doi.org/10.1177/ 2165143414544359

Shogren, K. A., Wehmeyer, M. L., Palmer, S. B., Rifenbark, G. G., \& Little, T. D. (2015). Relationships Between Self-Determination and Postschool Outcomes for Youth With Disabilities. The Journal of Special Education, 48(4), 256-267. https://doi.org/10.1177/0022466913489733s

Simoes, C., \& Santos, C. (2017). The impact of personal and Evironmental characteristic on quality of life of people with intellectual disability. Applied Research Quality Life, 12, 389-408. https://doi. org/10.1007/s11482-016-9466-7

Simplican, S. C., Leader, G., Kosciulek, J., \& Leahy, M. (2015). Defining social inclusion of people with intellectual and developmental disabilities: An ecological model of social networks and community participation. Research in Developmental Disabilities, 38, 18-29. https://doi.org/10.1016/j.ridd. 2014.10.008

Trist, E. L., Susman, G. I., \& Brown, G. R. (1977). An experiment in autonomous working in an American underground coal mine. Human Relations, 30(3), 201-236.

United Nations. (2015). Concluding Observations on the Initial Report of the European Union. Convention on the Rights of Persons with Disabilities. https://doi.org/10.1057/palgrave.development.11003 10

Vargo, S. L., \& Lusch, R. F. (2008). Service-dominant logic: Continuing the evolution. Journal of the Academy of Marketing Science, 36(1), 1-10. https://doi.org/10.1007/s11747-007-0069-6

Wasfi, R., Steinmetz-Wood, M., \& Levinson, D. (2017). Measuring the transportation needs of people with developmental disabilities: A means to social inclusion. Disability and Health Journal, 10(2), 356-360. https://doi.org/10.1016/j.dhjo.2016.10.008

Webster, A., Cumming, J., \& Rowland, S. (2017). Facilitating Self-Determination Through Education Planning. In Empowering Parents of Children with Autism Spectrum Disorder (pp. 135-154). Springer Singapore.

Wehmeyer, M. L. (2005). Self-Determination and Individuals with Severe Disabilities: Re-Examining Meanings and Misinterpretations. Research and Practice for Persons with Severe Disabilities, 30(3), 113-120. https://doi.org/10.2511/rpsd.30.3.113 
Wehmeyer, M. L., \& Shogren, K. A. (2016). Self-determination and choice. In Handbook of EvidenceBased Practices in Intellectual and Developmental Disabilities (pp. 561-584). Springer International Publishing.

Wolfensberger, W. (1998). A brief introduction to social role valorization: A high-order concept for addressing the plight of societally devalued people, and for structuring human services (3rd, revis ed.). Syracuse, NY: Syracuse University, Training Institute for Human Service Planning, Leadership and Change Agency.

Young, S. G., Jones, I. F., \& Claypool, H. M. (2016). Stimulus Threat and Exposure Context Modulate the Effect of Mere Exposure on Approach Behaviors. Frontiers in Psychology, 7, 1881. https://doi. org/10.3389/fpsyg.2016.01881

Zajonc, R. B. (1968). Attidudinal Effects of Mere Exposure. Journal of Personality and Social Psychology, 9(2), 1-27. https://doi.org/10.1037/h0025848

Zhang, D., Katsiyannis, A., \& Zhang, J. (2002). Teacher and Parent Practice on Fostering Self-Determination of High School Students with Mild Disabilities. Career Development for Exceptional Individuals, 25(2), 157-169. https://doi.org/10.1177/088572880202500205

Zhang, D., Wehmeyer, M. L., \& Chen, L.-J. (2005). Parent and Teacher Engagement in Fostering the Self-Determination of Students with Disabilities: A Comparison Between the United States and the Republic of China. Remedial and Special Education, 26(1), 55-64. https://doi.org/10.1177/07419 325050260010701

Publisher's Note Springer Nature remains neutral with regard to jurisdictional claims in published maps and institutional affiliations. 